Rev. Elet. em Gestão, Educação e Tecnologia Ambiental (e-ISSN: 2236-1170)

\title{
DESCARTE INDEVIDO DE PILHAS E BATERIAS: A PERCEPÇÃO DO PROBLEMA NO MUNICÍPIO DE FREDERICO WESTPHALEN - RS
}

\author{
Pedro Daniel da Cunha Kemerich ${ }^{1}$, Sabrina Altmeyer Mendes ${ }^{2}$, \\ Tatiane Hohm Vorpagel ${ }^{2}$, Maurício Piovesan ${ }^{2}$ \\ ${ }^{1}$ Professor do curso de Engenharia Ambiental - UFSM/CESNORS - FW. \\ ${ }^{2}$ Alunos do curso de Engenharia Ambiental - UFSM/CESNORS - FW. E-mail: sabrimendes92@hotmail.com
}

http://dx.doi.org/10.5902/223611706319

\section{RESUMO}

A crescente demanda de eletroeletrônicos no Brasil faz com que a utilização de pilhas e baterias seja proporcional ao consumo de aparelhos que as requerem para poderem funcionar. A carência de alternativas e a falta de informação da população fazem com que pilhas e baterias sejam destinadas em locais incorretos, podendo assim, acarretar sérios danos ambientais. Esses dispositivos possuem em sua composição metais pesados, que são altamente corrosivos e podem contaminar o solo, as plantas e o lençol freático; e também são potencialmente tóxicos podendo afetar a saúde humana. No Brasil, a questão da contaminação ambiental gerada por estes dispositivos apenas foi cogitada depois da década de 90; até então não havia nenhuma lei específica que dispusesse sobre pilhas e baterias. O presente trabalho tem como objetivo identificar as formas de descarte adotadas por usuários de pilhas e baterias na cidade de Frederico Westphalen - RS, bem como fazer um levantamento das informações e do conhecimento dos mesmos sobre possíveis danos causados por esses dispositivos pelo destino inadequado; para tal, um questionário contendo quatorze questões dissertativas foi aplicado na população do município em questão.

Palavras-Chave: questionário, contaminação, metais pesados.

\section{ABSTRACT}

The increasing demand for electronics in Brazil makes the use of batteries proportional to the consumption of appliances that requires it for work out. The lack of alternatives and information about it, mean that batteries are not allocated correctly, causing, posteriorly, seriously environmental damages. These gadgets have in its composition heavy metals, which are highly corrosive and also can contaminate the soil, plants and groundwater, besides, they are potentially toxic and may affect human health. In Brazil, the environmental contamination problem generated by these gadgets just was contemplated after 90's; until then, there was not a specific law that treats about batteries. This study has as objective identify disposal ways that can be adopted by users of this stuff in Frederico Westphalen - RS, as well as, make a survey of information and knowledge about the possible damages caused by the inappropriate disposal of this gadget. For that, a survey, containing fourteen essay questions, was applied to the people of the city in study.

Keywords: questionnaire, contamination, heavy metals. 
Rev. Elet. em Gestão, Educação e Tecnologia Ambiental (e-ISSN: 2236-1170)

\section{INTRODUÇÃO}

No final da década de 1970 surgiram os primeiros sinais de alerta sobre os perigos de se descartar baterias e pilhas usadas junto com o resíduo comum. A demanda na utilização de energia portátil é crescente em equipamentos eletroeletrônicos diversos. Isso provoca o crescimento da produção e do consumo de pilhas e baterias (ROCHA, 2004).

Todo dia pilhas são lançadas no meio ambiente por milhões de pessoas. Ao serem descartadas de forma inadequada, liberam seus componentes tóxicos no ambiente, contaminando o solo, a água, a atmosfera, podendo causar sérios danos a diversas formas de vida, incluindo o homem (SCHIO, 2003).

No Brasil, até a década de 1990, não se cogitava sobre a questão da contaminação ambiental por pilhas e baterias usadas. No entanto, desde 1999, o país possui legislação específica que dispõe sobre as pilhas e baterias que contêm mercúrio, chumbo e cádmio (Resoluções CONAMA: no 257, de 30/06/99; e no 263, de 12/11/99). Em 2008, a Resolução 257 foi revogada, entrando em vigor a Resolução 401 que define a destinação ambientalmente adequada das pilhas e baterias usadas, mesmo que essas não excedam a quantidade permitida de metais pesados. Essa medida legal mostra-se insuficiente para solucionar, na prática, o problema do descarte inadequado desses resíduos (REIDLER, 2002).

De acordo com a norma NBR 10.004, as pilhas e baterias apresentam características de corrosividade, reatividade e toxicidade, classificando-as como resíduos perigosos (classe I) (ABNT, 2004).

O descarte de pilhas no lixo doméstico é um fato extremamente grave. Com o passar do tempo, ocorre inevitavelmente a contaminação de plantas, solos e lençóis freáticos, devido a corrosão da blindagem da pilha disposta em aterros ditos controlados e lixões; com isso os metais pesados presentes liberados no ambiente tem a propriedade de bioacumulação por meio da cadeia alimentar gerando efeitos tóxicos no organismo humano e de outros animais. Por isso há a necessidade de uma destinação especial para este material (AFONSO et al, 2003).

Uma das soluções para esta problemática seria a reciclagem das pilhas, porém isto se torna extremamente difícil devido à natureza dos multicomponentes das mesmas. Os tratamentos propostos são, na sua grande maioria, consumidores de energia e apresentam elevada corrosividade tornando este processo não viável economicamente (LAUFFER, 2000).

Com base no tema exposto, o presente trabalho tem como objetivo identificar as formas de descarte das pilhas adotadas pela população do município de Frederico Westphalen - RS, bem como verificar o grau de conhecimento sobre os efeitos danosos da disposição incorreta destes materiais no solo.

\section{METODOLOGIA}

Para a realização desta pesquisa, foi elaborado um questionário com quatorze questões dissertativas referentes ao consumo e descarte de pilhas gerado pela população do município de Frederico Westphalen.

O questionário foi aplicado em escolas do município, em empresas e na praça central da cidade. Foram abordadas 100 pessoas de idade, escolaridade e renda variada em um universo amostral de 28.843 habitantes, ou seja, $0,347 \%$ da população local (IBGE, 2010). Dentre os itens abordados estão: consumo de diferentes tipos de pilha, formas de destino dado a elas e 
Rev. Elet. em Gestão, Educação e Tecnologia Ambiental (e-ISSN: 2236-1170)

conhecimento sobre possíveis danos à saúde humana e ao meio ambiente gerados pelo descarte incorreto.

As respostas obtidas foram analisadas, posteriormente relatadas e representadas graficamente para melhor visualização e discussão.

\section{Caracterização do local em estudo}

Frederico Westphalen é um município brasileiro do estado do Rio Grande do Sul. Localizase a uma latitude 2721'33" sul e a uma longitude 5323'40" oeste, estando a uma altitude de 566 metros e possui uma área de $264,976 \mathrm{~km}^{2}$ (IBGE, 2010).

A cidade tem se expandido cada dia mais e o meio rural vai dando espaço para as grandes propriedades; $18,71 \%$ da população vive no meio rural. Frederico é uma cidade com IDESE (Índice de Desenvolvimento Socioeconômico) e PIB (Produto Interno Bruto) de R\$ 343,734 mil, caracterizando-se assim como um dos municípios mais desenvolvidos da região (SANTI, 2010).

A rede hidrográfica do município pertence à bacia do Rio Uruguai; o clima descrito é subtropical úmido ( $\mathrm{Cfa}$ ), tendo chuvas bem distribuídas durante o ano. Dados do Laboratório de Agrometeorologia da Universidade Regional Integrada do Alto Uruguai e das Missões (URI-FW), mostram que a temperatura média anual é de $18^{\circ} \mathrm{C}$, podendo ocilar entre $6^{\circ} \mathrm{C}$ e $10^{\circ} \mathrm{C}$ no inverno e $31^{\circ} \mathrm{C}$ no verão (GIOVENARDI et al, 2008).

Dentre as atividades comerciais destacam-se a produção de carne de origem suína e de aves, além da produção de leite, frutas e fumo. Frederico Westphalen possui um dos maiores abatedouros de suínos do estado, a base agrícola circunda na produção de grãos como trigo, soja e milho e é considerada pólo econômico, social e cultural na Região Noroeste do Estado do Rio Grande do Sul (SANTI et al, 2009).

\section{RESULTADOS E DISCUSSÃO}

Com os resultados obtidos através da aplicação do questionário, foi possível tabelar dados como: nível escolar, idade, renda e consumo de pilhas feito pela população. A tabela 1 relaciona o grau de escolaridade com a média de idade dos entrevistados.

Tabela 1. Dados dos entrevistados.

\begin{tabular}{|c|c|c|c|c|c|c|}
\hline Escolaridade & $\begin{array}{c}\text { Fundamental } \\
\text { Incompleto }\end{array}$ & $\begin{array}{c}\text { Fundamental } \\
\text { Completo }\end{array}$ & $\begin{array}{c}\text { Médio } \\
\text { Incompleto }\end{array}$ & $\begin{array}{c}\text { Médio } \\
\text { Completo }\end{array}$ & $\begin{array}{c}\text { Superior } \\
\text { Incompleto }\end{array}$ & $\begin{array}{c}\text { Superior } \\
\text { Completo }\end{array}$ \\
\hline $\begin{array}{c}\text { Número de } \\
\text { pessoas } \\
\text { entrevistadas }\end{array}$ & 3 & 0 & 72 & 5 & 16 & 4 \\
\hline Média de idade & 55 & & 18 & 38 & 22 & 33 \\
\hline
\end{tabular}

Dos entrevistados, 72\% (72/100) eram jovens com 18 anos e ainda estavam cursando o ensino médio.

A tabela 2 mostra quantas pessoas possuem renda mensal, que varia de 1 a 5 salários mínimos, relacionando estes números com o grau de escolaridade. 
Rev. Elet. em Gestão, Educação e Tecnologia Ambiental (e-ISSN: 2236-1170)

Tabela 2. Renda mensal familiar baseada no salário mínimo nacional do ano de 2011.

\begin{tabular}{|c|c|c|c|c|c|c|}
\hline Escolaridade & $\begin{array}{c}\text { Fundamental } \\
\text { Incompleto }\end{array}$ & $\begin{array}{c}\text { Fundamental } \\
\text { Completo }\end{array}$ & $\begin{array}{c}\text { Médio } \\
\text { Incompleto }\end{array}$ & $\begin{array}{c}\text { Médio } \\
\text { Completo }\end{array}$ & $\begin{array}{c}\text { Superior } \\
\text { Incompleto }\end{array}$ & $\begin{array}{c}\text { Superior } \\
\text { Completo }\end{array}$ \\
\hline Menor que 1 & - & - & 10 & 2 & - & - \\
\hline 1 a 2 & - & - & 13 & - & 1 & - \\
\hline 2 a 5 & 3 & - & 24 & 2 & 5 & 2 \\
\hline Maior que 5 & - & - & 8 & 1 & 4 & - \\
\hline Não informa & - & - & 17 & - & 6 & 2 \\
\hline
\end{tabular}

Sobre a renda familiar, a maioria dos entrevistados (24\% (24/100)) ganhavam de 2 a 5 salários mínimos (baseado no salário mínimo nacional do ano de 2011 que era de $R \$ 545,00$, segundo a Lei $\mathrm{n} 0$ 12.382, de 25 de fevereiro de 2011.).

A tabela 3 apresenta a média do consumo anual de pilhas feito pela população.

Tabela 3. Média do consumo anual de pilhas feito pela população de Frederico Westphalen.

\begin{tabular}{|c|c|c|c|c|c|c|}
\hline Escolaridade & $\begin{array}{c}\text { Fundamental } \\
\text { Incompleto }\end{array}$ & $\begin{array}{c}\text { Fundamental } \\
\text { Completo }\end{array}$ & $\begin{array}{c}\text { Médio } \\
\text { Incompleto }\end{array}$ & $\begin{array}{c}\text { Médio } \\
\text { Completo }\end{array}$ & $\begin{array}{c}\text { Superior } \\
\text { Incompleto }\end{array}$ & $\begin{array}{c}\text { Superior } \\
\text { Completo }\end{array}$ \\
\hline $\begin{array}{c}\text { Média do } \\
\text { consumo } \\
\text { anual de } \\
\text { pilhas }\end{array}$ & 14 & - & 17 & 11 & 19,5 & 8 \\
\end{tabular}

Por ano, o consumo de pilhas pode chegar até a quantidade de 19,5 pilhas por pessoa. Essa maior aquisição foi feita por $16 \%$ (16/100) dos entrevistados, os quais possuíam ensino superior incompleto.

Dentre os entrevistados, 58\% (58/100) afirmaram comprar pilhas do tipo comum por serem mais baratas e, a maioria destes não tinham conhecimento da maior durabilidade das pilhas alcalinas (figura 1).

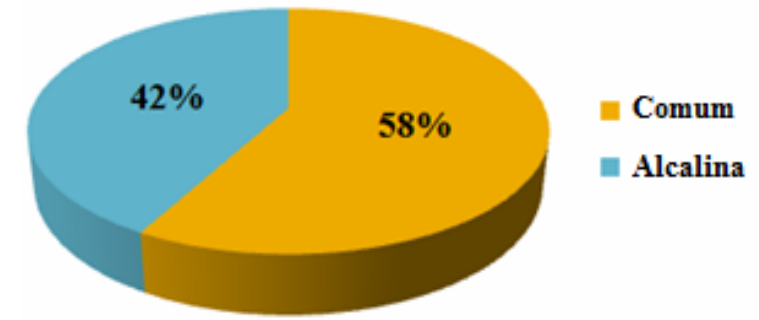

Figura 1. Gráfico do consumo de diferentes tipos de pilhas.

No Brasil, são produzidos 800 milhões de pilhas e 17 milhões de baterias por ano, sendo que $70 \%$ das pilhas fabricadas são as chamadas comuns ou zinco-carbono, os $30 \%$ restantes são referentes às pilhas do tipo alcalina (ABINEE, 1999).

A diferença básica entre a pilha alcalina e a de zinco-carbono é que, a primeira emprega célula eletroquímica com materiais ativos de maior grau de pureza (BOCCHI et al, 2000). O zinco (ânodo) produzido por processos eletroquímicos ou por destilação com alto teor de pureza $(99,85-$ $99,00 \% \mathrm{~m} / \mathrm{m}$ ) possui grande área superficial e tamanho uniforme de partícula, diminuindo a resistência interna e gerando alta densidade de energia (ALMEIDA et al, 2006). $\mathrm{O} \mathrm{MnO}_{2}$ de origem 
eletrolítica é misturado com grafite em pó (cátodo), minimizando problemas de corrosão. O grafite em pó aumenta a condutividade do cátodo, ampliando a faixa de temperatura de trabalho e o nível de descarga (REIDLER, 2002). Uma solução de $\mathrm{KOH}$ ( 30\%), com certa quantidade de ZnO (que retarda a corrosão do ânodo), atua como eletrólito (BERNARDES et al, 2004).

As pilhas alcalinas são mais resistentes a altas temperaturas, oferecem maior segurança contra vazamentos e duram de quatro a dez vezes mais que as $\mathrm{Zn}-\mathrm{C}$ dependendo do uso (BOCCHI et al, 2000), o que reflete no seu preço, tornando-se mais caras do que as pilhas $\mathrm{Zn}-\mathrm{C}$.

Quando questionados onde descartavam as pilhas que não possuíam mais utilidade, a maioria declarou jogá-las no lixo comum, e a minoria as guardava em caixas, queimava ou as destinava a pontos de coleta como representado pela figura 2.

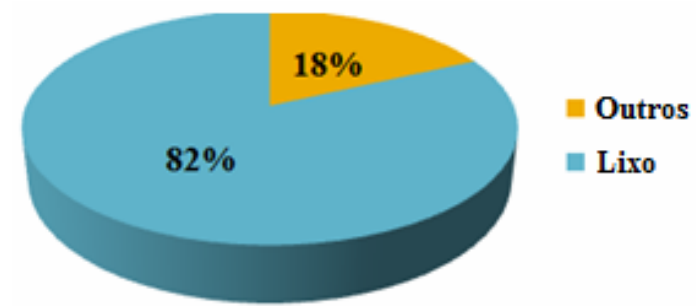

Figura 2. Gráfico da porcentagem da destinação de pilhas.

Um estudo feito com 100 educandos de 10 e $2 \%$ graus da cidade de São Vicente do Sul RS contradiz estes resultados, pois Brum e Silveira (2011) citam: "69\% dos entrevistados raramente descartam pilhas e baterias, e quando fazem, usam o lixo comum para efetuar 0 descarte".

O descarte de pilhas no solo ou no lixo urbano acarreta em sérios problemas nas estações de tratamento de lixo; ocorre também poluição das águas subterrâneas e superficiais, e ainda bioacumulação e biomagnificação de substâncias tóxicas na cadeia alimentar. Tanto zinco quanto manganês são tóxicos quando em concentrações elevadas (AGOURAKIS et al, 2006).

No país é produzido $2,6 \mathrm{Kg}$ de lixo eletrônico por habitante, o equivalente a menos de $1 \%$ da produção mundial de resíduos do mundo, porém, a indústria eletrônica continua em expansão (SMAAL, 2009).

A disposição inadequada, porém legalizada, das pilhas é feita nos lixões, isto é, em aterros não controlados para onde é destinada a maioria dos resíduos sólidos domiciliares do Brasil (AGOURAKIS et al, 2006). Aproximadamente cada bateria ou pilha depositada de forma errada no meio ambiente (figura 3) contamina uma área de cerca de um metro quadrado. Portanto, o dano ambiental pode ser ainda maior dependendo da quantidade de pilhas e baterias jogadas nos lixões (ROA et al, 2009). 


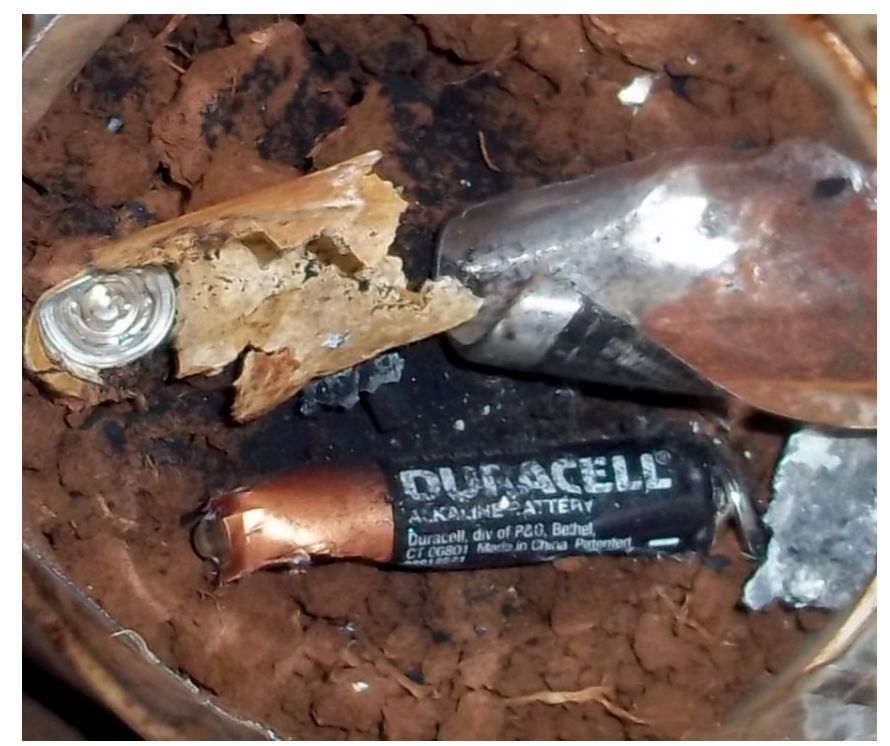

Figura 3. Imagem da disposição inadequada de pilhas no solo.

A figura 4 demonstra o percentual de pessoas que responderam sim ou não quando questionados se sabiam da presença de componentes tóxicos ao meio ambiente e à saúde humana presente nas pilhas; $90 \%$ (90/100) dizia ter conhecimento da presença dos componentes, porém somente $1 \%(1 / 100)$ dos que disseram sim tinham conhecimento de que esses componentes são os metais pesados.

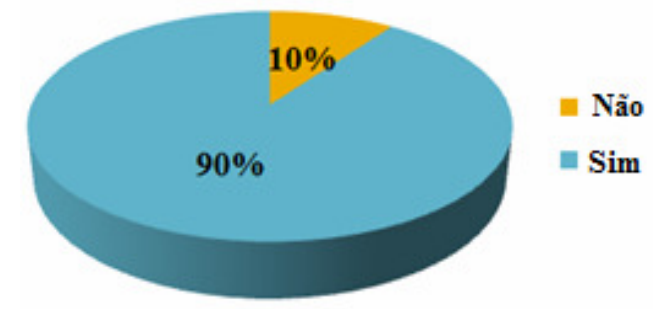

Figura 4. Gráfico da porcentagem dos entrevistados que sabem da toxicidade das pilhas.

Brum e Silveira (2011) em seu trabalho afirmam:

Também se observou que, nas questões, composição e danos à saúde, 36 e $46 \%$, consecutivamente, dos entrevistados, declararam não ter conhecimento da sua composição, nem ter conhecimento dos problemas que a contaminação por produtos como mercúrio, cobre e chumbo pode causar à saúde humana.

Dentre as substâncias que compõem as pilhas e baterias, há os metais pesados como: chumbo, níquel, cádmio, mercúrio, cobre, zinco, manganês, prata, entre outros. Com o descarte indevido destes materiais, os metais pesados presentes podem ser lixiviados infiltrando-se e contaminando o solo, o lençol freático e também a fauna e a flora das regiões próximas. Além disso, estes metais são bioacumulativos. Quando absorvidos pelo ser humano através da cadeia alimentar depositam-se no tecido ósseo e gorduroso, podendo provocar doenças que variam de lesões cerebrais a disfunções renais e pulmonares (ROA, 2009). 
A absorção de metais pelo organismo humano ocorre por inalação, ingestão e através da pele. Porém a distribuição, deposição, retenção e absorção dependem das propriedades físicoquímicas do material inalado (WOLFF \& CONCEIÇÃO, 2003).

Quando questionados sobre o conhecimento da reciclagem das pilhas exauridas, 63\% (63/100) responderam que não sabiam desta possibilidade e $37 \%$ (37/100) afirmaram saber que as pilhas podem ser recicladas por meios específicos como demonstra a figura 5 .

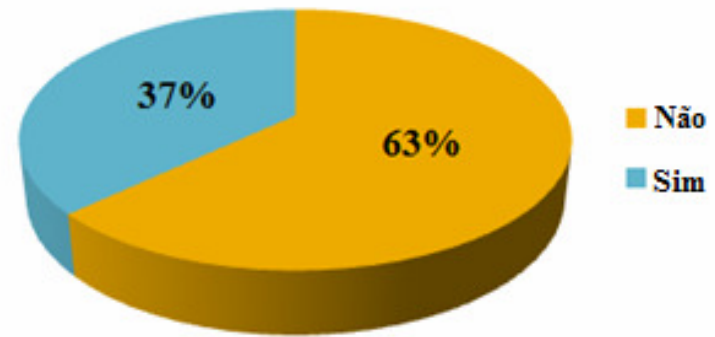

Figura 5. Gráfico do percentual de pessoas com conhecimento da possibilidade da reciclagem das pilhas.

No Brasil a ideia de coleta seletiva é recente, pilhas e baterias tiveram início no dia 22 de julho de 2000 e a reciclagem de alguns tipos de pilhas e baterias, começou no dia 22 de julho de 2001 (CONAMA, 1999).

Para promover a reciclagem de pilhas, é necessário inicialmente o conhecimento de sua composição. Em diferentes laboratórios têm sido realizadas pesquisas de modo a desenvolver processos para reciclar as baterias usadas ou, em alguns casos, tratá-las para uma disposição segura. Os processos de reciclagem de pilhas e baterias podem seguir três linhas distintas: a baseada em operações de tratamento de minérios, a hidrometalúrgica ou a pirometalúrgica. Algumas vezes estes processos são específicos para reciclagem de pilhas, outras vezes as pilhas são recicladas juntamente com outros tipos de materiais (TENÓRIO e ESPINOSA, 2006).

Sobre pontos de coleta das pilhas que não possuem mais utilidade, $71 \%$ (71/100) responderam saber da existência de algum e $29 \%$ (29/100) dos questionados não conheciam nenhum local de coleta na cidade (figura 6).

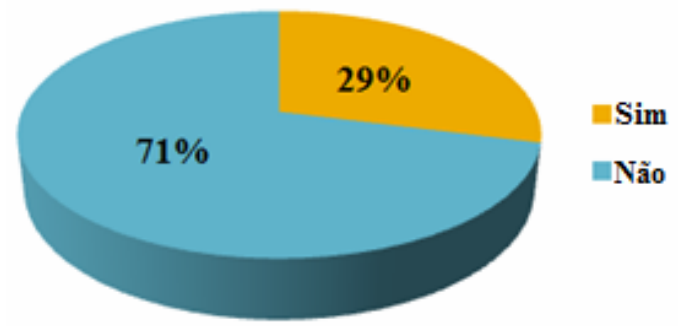

Figura 6. Gráfico do percentual de pessoas que conhecem pontos de coleta de pilhas na cidade de Frederico Westphalen - RS.

Devido à inexistência de estrutura de coleta e poucas empresas na área de reciclagem, o material coletado se tornou um problema para muitas cidades brasileiras. Em 2008 foi decretado que todos os pontos de venda de pilhas e baterias do país terão dois anos para oferecer aos 
Rev. Elet. em Gestão, Educação e Tecnologia Ambiental (e-ISSN: 2236-1170)

consumidores pontos de coleta para receber os produtos descartados, e caberá ao comércio varejista encaminhar o material recolhido aos fabricantes e importadores que, por sua vez, serão responsáveis pela reciclagem, ou, quando não for possível, pelo descarte definitivo em aterros sanitários licenciados (Resolução CONAMA nº 401 de 04/11/2008) .

Pelas informações obtidas, pode-se perceber que a maioria das pessoas entrevistadas não tinham interesse em participar de campanhas de conscientização quanto ao devido descarte destes materiais e, tampouco já tinham participado ou recebido instruções sobre o assunto em sua vida escolar.

\section{CONCLUSÃO}

A maioria da população do município de Frederico Westphalen - RS compra pilhas do tipo comum e quando não possuem mais utilidade, a maioria delas são descartadas no lixo comum. A comunidade tem conhecimento dos possíveis danos e perigos para a saúde humana e ao meio ambiente da composição de pilhas e baterias, mas não sabem que esses componentes são os metais pesados.

Pode-se perceber também, que a população sabe da existência de pontos de coleta destes materiais na cidade, porém não imaginam que pilhas e baterias podem ser recicladas; sendo assim não se preocupam com o destino correto que deveria ser dado a elas e tampouco se preocupam em buscar novas informações sobre o assunto.

\section{REFERÊNCIAS}

ABINEE. Associação Brasileira da Indústria Elétrica e Eletrônica. Disponível em: <www.abinne.gov.br >. Acessado em: 05/02/2012.

ABNT- ASSOCIAÇÃO BRASILEIRA DE NORMAS TÉCNICAS. NBR 10004: Resíduos sólidos - Classificação. 2 ed. São Paulo: ABNT, 2004a. 77p.

AFONSO, J. C. BARANDAS, A. P. M. G. SILVA, G. A. P. FONSECA, S. G. Processamento da pasta eletrolítica de pilhas usadas. Quím. Nova vol.26 no.4 São Paulo July/Aug. 2003.

AGOUKARIS, D. C.; CAMARGO, I. M. C.; COTRIM, M. B. Quim. Nova. 2006, 29, 960.

ALMEIDA, M. F.; XARÁ, S. M.; DELGADO, J.; COSTA, C. A. Waste Manage. 2006, $26,466$.

BERNARDES, A. M.; ESPINOSA, D. C. R.; TENÓRIO, J. A. S.; J. Power Sources 2004, 130, 291.

BOCCHI, N. FERRACIN, L. C. BIAGGIO, S. R. Pilhas e baterias: funcionamento e impacto ambiental. Disponível em:<http://www.qnesc.sbq.org.br/online/qnesc11/v11a01.pdf>. Acessado em: 10/02/2012.

BRASIL. Conselho Nacional de Meio Ambiente. Resolução, Conama n 401, de 04/11/2008. Estabelece os limites máximos de chumbo, cádmio e mercúrio para pilhas e baterias comercializadas no território nacional e os critérios e padrões para o seu gerenciamento ambientalmente adequado, e dá outras providências. Brasília: Diário Oficial da União, 04 nov. 2008.

BRASIL. Conselho Nacional de Meio Ambiente. Resolução, Conama ${ }^{\circ} 257$, de 30.06.99. Dispõe sobre o descarte e o gerenciamento ambientalmente adequado de pilhas e baterias usadas, no que tange à coleta, reutilização reciclagem, tratamento, ou disposição final. Brasília: Diário Oficial da União, 22 jun. 1999.

BRASIL. Conselho Nacional de Meio Ambiente. Resolução, Conama $n^{\circ} 263$, de 12.11.99. Dispõe sobre a inclusão, na Resolução Conama 257/99, das pilhas miniaturas e de botão, estabelecendo limites do teor de mercúrio por elemento. Brasília: Diário Oficial da União, 12 nov. 1999. 
Rev. Elet. em Gestão, Educação e Tecnologia Ambiental (e-ISSN: 2236-1170)

BRUM, Z. R. SILVEIRA, D. D. Educação ambiental no uso e descarte de pilhas e baterias. Revista Eletrônica em Gestão, Educação e Tecnologia Ambiental. Santa Maria - RS, vol.2, n²2, p. 205-213, 2011.

GIOVENARDI, R. DI MARE, R. A. SPONCHIADO, J. ROANI, S. H. JACOMASSA, F. A. F. JUNG, A. B. PORN, M. A. Revista Brasileira de Entomologia. Diversidade de Lepidoptera (Papilionoidea e Hesperioidea) em dois fragmentos de floresta no município de Frederico Westphalen, Rio Grande do Sul, Brasil. São Paulo - SP, 2008.

IBGE - Instituto Brasileiro de Geografia e Estatística. Censo 2010 de Frederico Westphalen - RS. Disponível em: http://www.ibge.gov.br/cidadesat/topwindow.htm?1. Acessado em: 12/02/2012.

LAUFFER, L. G. Anais do Seminário sobre Reciclagem de Resíduos Industriais, Companhia de Tecnologia de Saneamento Ambiental, São Paulo, Brasil, 2000.

Lei no 12.382, de 25 de fevereiro de 2011. Disponível em:< http://www.planalto.gov.br/ccivil_03/_Ato2011-2014/2011/Lei/L12382.htm>. Acessado em: 12/02/2012.

REIDLER, N. M. V. L. R. Resíduos gerados por pilhas e baterias usadas: uma avaliação da situação brasileira, 1999 - 2001. São Paulo (BR), 2002. Dissertação (Mestrado em Saúde Pública) - Faculdade de Saúde Pública, Universidade de São Paulo.

REIDLER, N. M. V. L. GÜNTHER, W. M. R. Impactos sanitários e ambientais devido aos resíduos gerados por pilhas e baterias usadas. XXVIII Congresso Interamericano de Ingeniería Sanitaria y Ambiental, Cancún México, 2002.

ROA, K. R. V. SILVA, G. NEVES, L. B. U. WARIGODA, M. S. Pilhas e baterias: usos e descartes $\mathbf{x}$ impactos ambientais. Caderno do professor. GEPEQ- USP: curso de formação continuada de professores, 2009. Disponível em: <http://www.cienciamao.if.usp.br/dados/aas/_indefinidopilhasebateria.arquivo.pdf>. Acessado em: 08/11/2011.

ROCHA, R. R. O. OLIVEIRA, R. M. CRUZ, T. G. S. O descarte de pilhas e baterias no brasil e o seu impacto no meio ambiente. 2004. Centro Superior de Educação Tecnológica - CESET, UNICAMP.

SANTI, H. C. DEVENS, P. WEBER, A. F. Aspectos da Comunicação Rural em Frederico Westphalen. Intercom - Sociedade Brasileira de Estudos Interdisciplinares da Comunicação. XXXII Congresso Brasileiro de Ciências da Comunicação - Curitiba, PR, 2009.

SANTI, H. C. O impresso no meio rural: a recepção do caderno Agro Negócio por produtores rurais do município de Frederico Westphalen. TCC I - Trabalho de Conclusão de Curso I. Curso de Comunicação Social - Jornalismo, UFSM, 2010.

SMAAL, B. Lixo eletrônico: o que fazer após o término da vida útil dos seus aparelhos? Disponível em:< http://www.tecmundo.com.br/2570-lixo-eletronico-o-que-fazer-apos-o-termino-da-vida-util-dos-seusaparelhos-.htm>. Acessado em: 09/08/2011.

SCHIO, R. Pilhas e baterias: um lixo perigoso. Disponível em: < http://www.redeaguape.org.br/artigo.php?id=27>. Acessado em: 08/02/2012.

TENÓRIO, J. A. S. ESPINOSA, D. C. R. Reciclagem de Pilhas e Baterias. Disponível em:< http://bvs.per.paho.org/bvsare/e/proypilas/pilas.pdf>. Acessado em: 21/08/2012.

WOLFF, E. H, CONCEIÇÃO, S. V. Resíduos sólidos: a reciclagem de pilhas e baterias no Brasil. 2003. Disponível em: <http://www.abepro.org.br/biblioteca/ENEGEP2001_TR104_0146.pdf>. Acessado em: 15/12/2011. 